\title{
Erratum to: Time-resolved OCT- $\mu$ PIV: a new microscopic PIV technique for noninvasive depth-resolved pulsatile flow profile acquisition
}

\author{
Chia-Yuan Chen • Prahlad G. Menon • \\ William Kowalski · Kerem Pekkan
}

Published online: 10 February 2013

(C) Springer-Verlag Berlin Heidelberg 2013

Erratum to: Exp Fluids (2013) 54:1426

DOI 10.1007/s00348-012-1426-x

The authors would like to correct errors in Table 1 of the original publication of the article.

The corrected Table 1 is given below:

Table 1 Optical data of various $\mu \mathrm{PIV}$ techniques for high Hct $(>10 \%)$ flow measurements

\begin{tabular}{lll}
\hline PIV method & Depth resolution & Max. imaging depth \\
\hline Stereo $\mu$ PIV & $10^{1} \mu \mathrm{m}^{\mathrm{a}}$ & $10^{1} \mu \mathrm{m}^{\mathrm{a}}$ \\
Confocal- $\mu$ PIV & $10^{0} \mu \mathrm{m}^{\mathrm{b}}$ & $10^{1} \mu \mathrm{m}^{\mathrm{c}}$ \\
OCT- $\mu$ PIV & $10^{1} \mu \mathrm{m}^{\mathrm{d}}$ & $10^{3} \mu \mathrm{m}^{\mathrm{d}}$ \\
\hline
\end{tabular}

$\bar{a}$ Data were acquired using the same optical set-up and objective as described in Lindken et al. (2006)

b Patrick et al. (2011), Lima et al. (2006)

c Patrick et al. (2011)

d Davis et al. (2009)

The online version of the original article can be found under doi:10.1007/s00348-012-1426-x.

\section{C.-Y. Chen}

Department of Mechanical Engineering, National Taiwan

University of Science and Technology, Taipei 10607, Taiwan

P. G. Menon - W. Kowalski - K. Pekkan

Departments of Biomedical and Mechanical Engineering,

Carnegie Mellon University, 700 Technology Drive,

Pittsburgh, PA 15219, USA

K. Pekkan ( $\square)$

Department of Mechanical Engineering, Koc University, Rumelifeneri, Istanbul, Turkey

e-mail: kpekkan@andrew.cmu.edu; kpekkan@ku.edu.tr 